\title{
Don't ignore a positive pregnancy test
}

\author{
D B Smith, G J S Rustin, K D Bagshawe
}

\section{Serum should be} assayed for

human chorionic gonadotrophin when a positive pregnancy test is not followed by an unequivocal diagnosis of pregnancy as a raised concentration suggests a trophoblastic tumour
Department of Medical Oncology, Charing Cross Hospital, London W6 8RF D B Smith, MD, senior registrar

G J S Rustin, MD, senior lecturer

K D Bagshawe, MD, professor

Correspondence to:

Dr Smith.
There are now at least 18 commercially available "over the counter" home pregnancy testing kits.' These kits rely on the presence of human chorionic gonadotrophin in the urine, which is detected using monoclonal antibodies raised against its $\beta$ subunit. In the presence of the hormone the formation of antibody/ human chorionic gonadotrophin complexes results in the agglutination of antibody coated red cells or latex particles or in some cases colour changes dependent on an anti-human chorionic gonadotrophin/alkaline phosphatase conjugate. These tests are now highly accurate and can detect hormone concentration down to $50 \mathrm{IU} / 1$ and will thus be positive eight to 14 days after the first missed period in pregnancy. The accuracy of the tests depends on carefully following the manufacturer's instructions. False negative results may be due to using too little urine or urine that is too old, to traces of detergent in the urine container, to reading the test too soon, or to disturbing the test container. False positive results may also be caused when tests are not performed correctly, by the ingestion of certain drugs such as phenothiazines, by heavy proteinuria or haematuria, by raised gonadotrophin concentrations around the menopause, or by raised human chorionic gonadotrophin concentrations for other reasons. We report on two patients to show the importance of following up apparently false positive results of pregnancy tests.

\section{Case reports}

Case 1-A 25 year old woman was admitted to hospital with severe breathlessness in September 1987. She had had a spontaneous abortion in 1981 and then took the contraceptive pill until 1985. After she stopped taking the pill her periods were irregular and on four occasions the results of pregnancy tests bought over the counter were positive. She was twice referred for ultrasound examinations, but each time the uterus was empty and no further action was taken. In April 1987 dysfunctional uterine bleeding was diagnosed, and she was treated with clomiphene. She then had intermittent pleuritic chest pain and breathlessness on exertion. Chest $x$ ray films showed changing shadows but computed tomography and bronchoscopy gave negative results. In early September she was admitted with acute breathlessness and chest pain. A further pregnancy test was positive and results of laparoscopy of the pelvis normal. A radioisotope ventilationperfusion lung scan showed multiple filling defects in the left lung and no perfusion to the right. A presumptive diagnosis of choriocarcinoma was made with the syndrome of tumour growing in the pulmonary arteries. ${ }^{2}$ She was given anticoagulant drugs and treated with chemotherapy using the etoposide with methotrexate, actinomycin D (EMA), and vincristine and cyclophosphamide (CO) protocol. ${ }^{3}$ The serum concentration of human chorionic gonadotrophin fell from $103000 \mathrm{IU} / 1$ to normal (<2 IU/l) within eight weeks and respiratory function also improved rapidly. She now leads a normal life but remains breathless on exertion.

Case 2-A 32 year old woman was admitted to hospital in March 1988 with acute lower abdominal pain. A pregnancy test was positive, and she underwent laparoscopy for suspected ectopic pregnancy. A macroscopic tumour was found on the surface of the right ovary and a right salpingo-oophorectomy was carried out. A subsequent histological examination showed choriocarcinoma and her serum human chorionic gonadotrophin concentration was $105000 \mathrm{IU} / \mathrm{l}$. Seven days after laparotomy she developed a headache and right lower quadrantanopia. Computed tomography of the brain showed a left occipital mass which was resected and she was then treated with chemotherapy using the etoposide with methotrexate, actinomycin D (EMA), and vincristine and cyclophosphamide (CO) regimen. ${ }^{3}$ Serum concentrations of human chorionic gonadotrophin fell to normal and chemotherapy was continued until August.

She had delivered a normal baby girl in 1982 and then took the oral contraceptive pill until 1985. Shortly after stopping the pill she became pregnant but had a spontaneous abortion at 14 weeks and dilatation and curettage. She did not restart the pill, but her periods remained irregular and at laparoscopy in August 1987 no abnormality was seen. She was then treated with clomiphene for nine months. From 1985-8 she had two positive results from over the counter pregnancy tests and one negative test performed by the pharmacist. After each test she was told that the results were unreliable in early pregnancy and no action was taken.

\section{Discussion}

Early testing for pregnancy may contribute to improved antenatal care by allowing women to alter their dietary or smoking habits to the benefit of the fetus. In addition, it would be an advantage where termination is required on medical grounds. Home pregnancy tests offer an apparently highly effective method for detecting pregnancy early and their use is increasing rapidly. Manufacturers claim that the test kits are about $98 \%$ accurate when carried out under ideal conditions. The women who perform the tests, however, often have no previous experience of the methods, and despite explicit written instructions errors are likely to occur. Errors in performing the tests more often lead to a false negative than a false positive result. For example, with tests that rely on the visual detection of haemagglutination any excess vibration of the container, such as might be caused by a nervous patient, may disturb the agglutinated cells and give a false negative result. Despite the known problems with the tests exact data on the frequency of false positive and false negative results do not exist. This is in part due to the confidentiality that women may seek by carrying out a test at home.

The two cases we report show the importance of seeking a clear explanation for a false positive result of a pregnancy test. If the test has been performed correctly and proteinuria and drug interference, for instance, are ruled out then a raised human chorionic gonadotrophin concentration, particularly in young women, is virtually certain. In most cases this will be due to a pregnancy that ends in a first trimester abortion (up to $15 \%$ of all pregnancies ${ }^{4}$ ), but in a small minority it will be due to the hormone producing a tumour such as 
choriocarcinoma. Such patients often have a history of menstrual dysfunction and may have had many positive tests. Some patients, as in the second case, will have both positive and negative test results. The most likely explanation for this is that the negative test result came from a less sensitive kit. Patients with choriocarcinoma may have relatively low human chorionic gonadotrophin concentrations for months or years before the disease enters a rapid growth phase, and during this time tests with a sensitivity of $500 \mathrm{IU} / 1$ may be negative. Thus follow up tests should always be carried out with a kit of the same sensitivity as the original test.

With modern combination chemotherapy choriocarcinoma has a high cure rate even when there are metastases. ${ }^{3}$ But when the diagnosis is delayed patients may die unnecessarily or suffer avoidable morbidity as in our two cases. The correct interpretation of "false positive" pregnancy tests might go some way to eliminating such unfortunate occurrences.

We recommend that all patients who have a pregnancy test that appears to be falsely positive should have their serum human chorionic gonadotrophin concentration measured. Under such circumstances a raised concentration would strongly suggest the presence of trophoblastic tumour.

1 Anonymous. A year for new arrivals. Chemist and Druggist 1987;2:10-15.

2 Bagshawe KD, Begent RHJ. Trophoblastic tumours: clinical features and management. In: Coppleson M, ed. Gynaecologic oncology. Vol 2. Edinburgh Churchill Livingstone, 1981:757-72.

3 Newlands ES, Bagshawe KD, Begent RHJ, Rustin GJSR, Holden L, Dent J. Developments in chemotherapy for medium- and high-risk patients with gestational trophoblastic tumours (1979-84). Br $\mathcal{F}$ Obstet Gynaecol 1986; 93:63-9.

4 Edmonds DK, Lindsay KS, Miller JF, Williamson E, Wood PJ. Early embryonic mortality in women. Fertility and Sterility 1982;38:447-53.

(Accepted 16 August 1988)

\section{Maudsley of the Maudsley}

\section{Tony Delamothe}

"A lot of people coming at the nineteenth century from different angles have found themselves bumping into Henry Maudsley and wanting to know more about him," said Dr G E Berrios on why he had organised a symposium devoted to Henry Maudsley (1835-1918). Most of those who had bumped into him were at Robinson College, Cambridge, to share their experiences.

Not everyone from the "first rank of nineteenth century intellectual glitterati" has a symposium commemorating the 70th anniversary of their death. What brought the participants together was a sense of urgency: Maudsley, already insubstantial by the time of his death, is in danger of vanishing completely.

Quoted approvingly by Charles Darwin and read by Tolstoy, Maudsley's books are now being disposed of by librarians on the grounds that they are out of date. According to Maudsley's bibliographer, Professor Michael Collie, the New York Academy of Medicine has apparently lost its Maudsley collection, and the complete library of the West London Hospital, where Maudsley worked for many years, has disappeared without trace. ${ }^{\prime}$

When it comes to more personal details there has been less to lose. In his last book Religion and Realities (1918) Maudsley wrote that it was a ludicrous display of vanity by men of great eminence to leave behind them carefully preserved letters and elaborate memoirs of what they thought and felt. At least he had the consistency to leave almost none himself-not by giving instructions that his papers be destroyed (which only draws attention to them) but by destroying them himself. All that was left was a 4000 word biography marked private, written sometime in his $70 \mathrm{~s}$, which dealt mostly with his childhood and schooling.

Two of the Maudsley Lectures, given in his honour, have been biographical. Sir Aubrey Lewis's of 1951 was published (and is most historians' starting point); Sir Hubert Bond's of twenty years earlier, entitled "Maudsley: Testimonied in his own bringing forth" has been lost.

This makes it difficult for biographers in an age when personality is meant to unlock the secrets of a person's work. Fulsome obituaries rarely provide insights into people's lives, but in Maudsley's case, apart from his biographical fragment, obituaries are almost all there is. For what it's worth "cynical," "pessimistic," and "materialist" appear in nearly all of Maudsley's. "A great man, but not a good man. A right bastard," thought Dr Henry Rollin, present day chairman of the Royal College of Psychiatrists Group for the History of Psychiatry, freed from the obituarists' pieties. If only he had had children, the obituarists thought, perhaps his sympathies might have been wider.

Leaving so little for posterity may be counter productive: those who come later have an irresistible urge to fill the gap. Miss Patricia Allderidge, archivist and curator of the Bethlem Royal Hospital, attributed much of Maudsley's behaviour to his Yorkshire roots - "not just a Yorkshireman, but an extreme form of Yorkshireman"-making him seem like the Geoffrey Boycott of Victorian psychiatry.

At the other end of his life when Maudsley was virtually a recluse Dr Rollin detected depression, perhaps brought on by his wife's dementia (she died of "senile decay" in 1911). Maudsley's mother had died before he was 10, after which his father had hardly spoken. Was some pattern being repeated here?

The big unexplained "problem" of Maudsley's professional life was his resignation of the editorship of the Fournal of Mental Science in 1878. Was it because his critics could complain of "certain doctrines taught there, certain tenets, which are contrary and repugnant," or of his failure to advance the interests of asylum doctors? Why had Maudsley leant over backwards to insult in print his brother in law, asylum doctor Harrington Tuke, whom he had already finessed out of rewards Tuke thought were coming his way? Dr Charlotte Mackenzie, lecturer in history at Rolle College, Exmouth, gave a persuasive account of the likely basis for professional and personal rivalries between the men and why it might have come to a head in the 1870s. But then there was Crichton Browne's reminiscence that along with other psychiatrists Maudsley and Tuke would meet in Soho restaurants "to adumbrate projects for the future of lunacy,"-hardly suggesting they were implacable enemies. ${ }^{2}$

What genuinely separated Maudsley from his colleagues was his opposition to traditional religious beliefs. Being a dissenter from Yorkshire helped, but his time at University College Hospital spent reading Spencer and Comte in preference to dissection and

\section{London WC1H 9JR}

Tony Delamothe, $\mathrm{MD}$, assistant editor 